\title{
Effect of olprinone on liver microstructure in rat partial liver transplantation.
}

\section{$\operatorname{AUTHOR}(S):$}

Yamanaka, Kenya; Hatano, Etsuro; Iguchi, Khota;

Yamamoto, Gen; Sato, Motohiko; Toriguchi, Kan; Tanabe, Kazutaka; ... Nagata, Hiromitsu; Taura, Kojiro; Uemoto, Shinji

\section{CITATION:}

Yamanaka, Kenya ... [et al]. Effect of olprinone on liver microstructure in rat partial liver transplantation.. The Journal of surgical research 2013, 183(1): 391-396

\section{ISSUE DATE:}

2013-07

URL:

http://hdl.handle.net/2433/175671

\section{RIGHT:}

(C) 2013 Elsevier Inc:; This is not the published version. Please cite only the published version.; この論文は出版社版でありません。引用の際に は出版社版をご確認ご利用ください。 
Revised, October 24, 2012

\section{Effect of olprinone on liver microstructure in rat partial liver transplantation}

Kenya Yamanaka, MD, PhD; Etsuro Hatano, MD, PhD; Khota Iguchi, MD; Gen Yamamoto, MD;

Motohiko Sato, MD; Kan Toriguchi, MD; Kazutaka Tanabe, MD; Kenji Takemoto, MD; Kojiro

Nakamura, MD; Noriyuki Koyama, MD; Masato Narita, MD, PhD; Hiromitsu Nagata, MD, PhD;

Kojiro Taura, MD, PhD; Shinji Uemoto, MD, PhD

Department of Surgery, Graduate School of Medicine, Kyoto University

Running title: Effect of olprinone in partial liver transplantation

Category: Transplantation/Immunology

Address correspondence to:

Etsuro Hatano, $\mathrm{MD}, \mathrm{PhD}$

Department of Surgery, Graduate School of Medicine, Kyoto University

54 Kawaharacho, Shogoin, Sakyo-ku, Kyoto 606-8507, Japan

Tel: 81-75-751-4323, Fax: 81-75-751-4348

E-mail: etsu@kuhp.kyoto-u.ac.jp 


\section{Abstract}

Background. Donor safety is a major concern in living-donor liver transplantation. However, partial grafts do not meet the functional demands of recipients and lead to small-for-size syndrome (SFSS).

In a previous study, we showed that olprinone (OLP), a selective phosphodiesterase III inhibitor, upregulates endothelial nitric oxide synthase level in the liver and attenuates shear stress, sinusoidal endothelial cell injury, and hepatocyte apoptosis after excessive liver resection in a rat model. We aimed to examine whether OLP treatment has beneficial effects on SFSS in a rat model of partial liver transplantation (PLT).

Materials and Methods. Experiments were performed in a rat model of 30\% PLT. In the OLP group, an osmotic pump with OLP was inserted into the peritoneal cavity $48 \mathrm{~h}$ before liver graft sampling.

Recipient rats were not treated with OLP. We examined the liver microstructure by electron microscopy and biochemical examination, and determined the 7-day survival of the recipients.

Results. In the OLP group $1 \mathrm{~h}$ after PLT, the sinusoidal endothelial cells of the liver were well preserved and few vacuolar structures in hepatocytes were observed. The total serum bilirubin level 1 week after PLT tended to be lower in the OLP group than in the controls, and the liver microstructures were also well preserved in the OLP group. The probability of survival in the OLP group $(100 \%, 14 / 14$ rats) was significantly higher than that in the control group $(75 \%, 15 / 20$ rats).

Conclusions. OLP treatment was demonstrated to have therapeutic potential to overcome SFSS. 
Key words: olprinone, small-for-size syndrome, liver injury, microstructure 


\section{Introduction}

Adult-to-adult living-donor liver transplantation (A-LDLT) has become an alternative to deceased-donor liver transplantation [1]. One of the advantages of A-LDLT is reduction in waiting time and dropouts. However, donor safety remains a major concern. With regard to donor operations, the overall complication rate was reported to be significantly higher in the right-lobe graft group than in the left-lobe graft group [2]. The use of minimal graft volume to reduce the perioperative risk for living donors has been discussed [3].

However, partial grafts do not meet the functional demands of the recipient and lead to liver failure, which is referred to as small-for-size syndrome (SFSS) [3]. Liver blood flow per unit immediately increases after partial liver transplantation (PLT), and increased blood flow in the portal vein exerts shear stress, thereby affecting the liver [3, 4]. Excessive shear stress causes liver injuries such as hepatocyte apoptosis and necrosis and sinusoidal endothelial cell injury [4]. SFSS is characterized by postoperative liver failure from shear stress due to excessive portal flow to the liver $[3,5]$. Various animal experiments have been performed to establish treatments for SFSS, including splenectomy [6], portosystemic shunt placement [7], ischemic preconditioning [8], and pharmacological modifications $[9,10]$. Splenectomy is performed to reduce portal pressure if the portal pressure after reflow is greater than $15 \mathrm{mmHg}$ to achieve intentional portal pressure control [11]. 
Olprinone (OLP) has been clinically administered to patients with heart failure and to those undergoing cardiac surgery. It is a selective phosphodiesterase (PDE) III inhibitor with combined positive inotropic and vasodilator properties that are mediated by the elevation of intracellular cyclic adenosine monophosphate (cAMP) levels in vascular smooth muscle cells and cardiomyocytes by the prevention of cAMP degradation [12]. Nitric oxide produced by endothelial nitric oxide synthase (eNOS) plays an important role in reducing sinusoidal constriction during the early phase [13]. The importance of eNOS in hepatic injury after cold/warm reperfusion in transplanted liver grafts has been investigated [14]. In a previous study, we showed that OLP treatment upregulates eNOS levels in the liver and attenuates shear stress after excessive liver resection in rats to protect against sinusoidal endothelial cell injury and hepatocyte apoptosis [15]. Furthermore, OLP has been reported to protect the liver against ischemia-reperfusion injury (IRI) through an increase in cAMP levels and cytokine production [16]. IRI is a major cause of primary non-function of liver graft after liver transplantation. Moreover, IRI reduces liver regeneration after hepatectomy [17]. Therefore, OLP may be effective in overcoming SFSS and extending the minimum limits of the graft/recipient weight ratio.

The purpose of this study was to examine whether OLP preconditioning has a beneficial effect on SFSS in a rat model of PLT, with a particular focus on OLP's potential hepatoprotective effect on the microstructure of the graft liver. 


\section{Materials and Methods}

Animals

Inbred male Lewis rats (age, 9 to 10 weeks; body weight, 240-280 g; SLC, Sizuoka, Japan)

were used in this study. The rats were housed in a standard animal laboratory with free access to

water and chow. The animals were kept under constant environmental conditions, with a 12-h

light-dark cycle. All animal experiments were approved by the Animal Research Committee of Kyoto University. All animals were cared for in accordance with the National Institutes of Health (NIH) Guidelines for the Care and Use of Laboratory Animals.

Experimental Design and Surgical Procedure

The experiment was conducted in 2 groups of rats: an OLP-treated group and a control group. In the OLP group, rats were given $0.6 \mu \mathrm{g} / \mathrm{kg} / \mathrm{min}$ OLP (a kind gift from Eizai Pharmaceutical Co, Ltd, Japan) using an Alzet osmotic pump (Model 2001; Durect Corp., Cupertino, CA, USA) that was inserted into the peritoneal cavity under sevoflurane anesthesia (Abbott, Japan, Osaka, Japan) 48 $\mathrm{h}$ before the donor liver was harvested. Alzet peritoneal pump placement was used to ensure the steady administration of continuous OLP. OLP was not administered to recipient rats in this study. In the control group, preconditioned was not performed. 
In this study, we used a rat model of 30\% PLT without arterial reconstruction using the cuff method as an SFSS model $[18,19]$. After ligation of the middle and right Glisson's sheath, the liver was perfused with $10 \mathrm{~mL}$ of lactated Ringer's solution through the portal vein. The right and caudate lobes of the liver were selected to be grafted on the back table. The graft was stored in cold Ringer's solution, and the cold ischemia time was $50 \mathrm{~min}$. During liver transplantation, the portal vein was clamped for $20 \mathrm{~min}$. There were no differences in the ischemia reperfusion time between the 2 groups. After surgery, the rats were given food and water ad libitum. Donor operation was performed after intraperitoneal administration of $25 \mathrm{mg} / \mathrm{kg}$ pentobarbital, and recipient operation was performed under inhalation anesthesia with sevoflurane and ether. No immunosuppressive agent was administered to the recipient rats.

Electron Microscopy

We examined the morphology of endothelial cells and hepatocytes by using scanning electron microscopy (SEM) and transmission electron microscopy (TEM). Liver samples from both groups were collected $1 \mathrm{~h}$ after portal venous reperfusion. The samples were prepared for electron microscopy as described previously [15]. Furthermore, these samples were compared with 3 samples collected from each liver at 7 days after 30\% PLT with and without OLP preconditioning and after whole liver transplantation. 
Biochemical Examination

Blood samples were collected from survivors 1 week after PLT. Serum samples were

stored at $-80^{\circ} \mathrm{C}$ for measuring serum aspartate aminotransferase (AST), alanine aminotransferase (ALT), total bilirubin (T-Bil), and hyaluronic acid (HA) levels. Measurements were carried out by Japan Clinical Laboratories, Inc.

Survival Study

A total of 14 rats in the OLP group and 20 rats in the control group were used for the

survival study. The OLP group operations were performed after those of the control group. All PLTs were performed consecutively. Rats that lived for 7 days after PLT were considered survivors.

Statistical Analysis

Student's $t$-test was used to detect differences in the means of continuous measurements. A

$P$ value of less than 0.05 indicated statistical significance. All tests were 2-tailed. Probability of survival was calculated using the Kaplan-Meier method and examined with the log-rank test. JMP for Windows 8.0 (SAS Institute, Cary, NC, USA) was used for all statistical analyses.

\section{Results}


(1) Microstructure of the liver was well preserved in the OLP group1 $h$ after PLT

In the control group, SEM performed $1 \mathrm{~h}$ after PLT showed that the architecture of the sieve plate arrangement was fused and enlarged (Figure 1A). TEM showed that the sinusoidal wall was disrupted, and that microvilli extending from the parenchymal cell surface were damaged (Figure 1B). Vacuolar structures were observed in the cytoplasm of hepatocytes in the control group. In contrast, the architecture of the sieve plate arrangement in the OLP group was well preserved, and a thin layer of fenestrated endothelium was covered with the space of Disse, which was filled with microvilli (Figure 1C). Few vacuolar structures were observed in the OLP group (Figure 1D). These results indicate that OLP preconditioning preserves the microstructure of sinusoidal endothelial cells and hepatocytes against shear stress and IRI in the early phase after reperfusion.

(2) OLP treatment attenuated hepatocyte and sinusoidal endothelial cell injury 1 week after PLT

We evaluated the liver microstructure 1 week after PLT. In the PLT rats without OLP treatment, severe vacuolar degeneration was observed in the liver and the structure of sinusoidal endothelial cells was disrupted (Figure 2A). In contrast, in the OLP group, SEM showed well-preserved architecture of the sieve plate arrangement. In addition, TEM showed that the space of Disse was filled with microvilli; furthermore, no obvious hepatocyte structural disorder could be observed (Figure 2B). In the total liver transplantation model, no vacuolar degeneration was 
observed, and the structure of the sinusoidal endothelial cells was well preserved (Figure 2C).

Therefore, the microstructure of the liver in the OLP group was well preserved 1 week after PLT, similar to that after total liver transplantation.

We also estimated liver function by performing biochemical examination. Biloma was observed at the resected end of the graft liver, with the incidence being $30 \%(4 / 14)$ and $20 \%(3 / 20)$ in the OLP and control groups, respectively. Survivors with biloma were excluded from the biochemical examination. The average T-Bil levels of the control and OLP groups were 1.03 and 0.63 , respectively $(P=0.46)$. Although the serum T-Bil level tended to be higher in the control group, the average values for AST, ALT, and HA were similar in both groups (Figure 3).

(3) Probability of survival was improved in the OLP group

The probability of survival in the OLP group $(100 \%, 14 / 14$ rats) was significantly higher than that in the control group $(75 \%, 15 / 20$ rats) (Figure $4 ; P=0.0478)$. Postoperative bleeding and biloma were not observed in non-survivors. The cause of death was thought to be postoperative liver failure, although 3 of the 5 non-survivors also showed diffuse lung inflammation.

\section{Discussion}

OLP is reported to have the potential to protect the intestine, kidney, and heart against IRI, 
with liver being an exception. An anti-inflammatory effect and improvement of microcirculation through an increase in cAMP levels are considered to be the mechanisms underlying organ protection [20-22]. We previously reported that OLP preconditioning upregulated eNOS protein levels in the liver and attenuated sinusoidal endothelial cell injury due to excessive shear stress [15]. In this study, we demonstrated that the microstructure of sinusoidal endothelial cells from OLP-treated grafts can also be preserved well in the early phase after 30\% PLT in rats. The significant changes in hepatic microcirculation after PLT were transient and occurred mainly in the acute phase after reperfusion [23]. Therefore, preservation of microstructures in the early phase would be expected to result in a significant improvement in the 7-day survival. In addition, vacuolar structures were observed in the control group, whereas little vacuolar degeneration was observed in the OLP group. The increase in vacuolar degeneration in the early phase of liver transplantation and the extent of vacuolation observed after warm ischemia has been correlated with primary non-function and degree of hepatocellular damage [24]. Therefore, OLP treatment can also reduce hepatocyte damage caused by cold/warm IRI. This protective effect of OLP is expected to lead to a survival benefit.

The control of the early mechanical injury caused by excessive shear stress and cold/warm reperfusion may be a promising surgical strategy for SFSS. Several studies with animal models have shown that pharmacological modification to reduce portal pressure can have a protective effect on 
the liver in SFSS $[9,10,25]$. However, few pharmacological agents have actually been used in clinical practice. OLP has been clinically administered to patients with heart failure and to those undergoing cardiac surgery. OLP can be administered to patients undergoing liver surgery for liver protection more easily than other agents that are not clinically applicable. However, clinical trials are required to examine safety and efficacy and to establish an effective regimen to administer pharmacological agents with therapeutic potential. Therefore, we are performing a prospective trial to determine the safety of perioperative OLP administration for liver resection (UMIN000004975). OLP preconditioning was shown to have a protective effect on the microstructure of the liver in the early phase after PLT and improve survival in a rat model of SFSS. Furthermore, the protective effect of OLP on the microstructure of the liver was observed 1 week after PLT. Thus, OLP has therapeutic potential to overcome SFSS.

\section{Acknowledgments}

The authors wish to thank Eizai Pharmaceutical Co, Ltd (Japan) for their kind gift of OLP, and acknowledge the support of the Division of Electron Microscopic Study (Center for Anatomical Studies, Graduate School of Medicine, Kyoto University). 


\section{References}

1. Kaido T, Uemoto S. Does living donation have advantages over deceased donation in liver transplantation? J Gastroenterol Hepatol 2010; 25: 1598.

2. Iida T, Ogura Y, Oike F, et al. Surgery-related morbidity in living donors for liver transplantation. Transplantation. 2010; 89:1276.

3. Clavien PA, Petrowsky H, DeOliveira ML, et al. Strategies for safer liver surgery and partial liver transplantation. N Engl J Med. 2007; 356: 1545.

4. Garcea G, Maddern GJ. Liver failure after major hepatic resection. J Hepatobiliary Pancreat Surg 2009;16:145-155.

5. Dahm F, Georgiev P, Clavien PA. Small-for-size syndrome after partial liver transplantation: definition, mechanisms of disease and clinical implications. Am J Transplant 2005; 5: 2605 .

6. Glanemann M, Eipel C, Nussler AK, et al. Hyperperfusion syndrome in small-for-size livers. Eur Surg Res 2005; 37: 335.

7. Nakano T, Lai CY, Goto S, et al. Significance of portosystemic shunt on graft survival in liver transplantation: a rat model. Transplant Proc 2008; 40: 2515.

8. Eipel C, Glanemann M, Nuessler AK, et al. Ischemic preconditioning impairs liver regeneration in extended reduced-size livers. Ann Surg 2005; 241: 477. 
9. Man K, Lee TK, Liang TB, et al. FK 409 ameliorates small-for-size liver graft injury by attenuation of portal hypertension and down-regulation of Egr-1 pathway. Ann Surg 2004; 240: 159.

10. Xu X, Man K, Zheng SS, et al. Attenuation of acute phase shear stress by somatostatin improves small-for-size liver graft survival. Liver Transpl 2006; 12: 621.

11. Ogura Y, Hori T, El Moghazy WM, et al. Portal pressure $<15 \mathrm{~mm} \mathrm{Hg}$ is a key for successful adult living donor liver transplantation utilizing smaller grafts than before. Liver Transpl 16: 718.

12. Bender AT, Beavo JA. Cyclic nucleotide phosphodiesterases: molecular regulation to clinical use. Pharmacol Rev 2006; 58: 488.

13. Man K, Fan ST, Lo CM, et al. Graft injury in relation to graft size in right lobe live donor liver transplantation: a study of hepatic sinusoidal injury in correlation with portal hemodynamics and intragraft gene expression. Ann Surg 2003; 237: 256.

14. Theruvath TP, Zhong Z, Currin RT, et al. Endothelial nitric oxide synthase protects transplanted mouse livers against storage/reperfusion injury: Role of vasodilatory and innate immunity pathways. Transplant Proc 2006; 38: 3351.

15. Yamanaka K, Hatano E, Narita M, et al. Olprinone attenuates excessive shear stress through up-regulation of endothelial nitric oxide synthase in a rat excessive hepatectomy model. Liver Transpl 2011; 17: 60. 
16. Yamaguchi K, Kawahara T, Kumakura S, et al. Effect of olprinone, a phosphodiesterase III inhibitor, on hepatic ischemia-reperfusion injury in rats. Shock 2010; 33: 436.

17. Franco-Gou R, Peralta C, Massip-Salcedo M, et al. Protection of reduced-size liver for transplantation. Am J Transplant 2004; 4: 1408.

18. Kamada N, Calne RY. Orthotopic liver transplantation in the rat. Technique using cuff for portal vein anastomosis and biliary drainage. Transplantation 1979; 28: 47.

19. Selzner N, Selzner M, Tian Y, et al. Cold ischemia decreases liver regeneration after partial liver transplantation in the rat: A TNF-alpha/IL-6-dependent mechanism. Hepatology 2002; 36: 81.

20. Crisafulli C, Mazzon E, Galuppo M, et al. Olprinone attenuates the development of ischemia/reperfusion injury of the gut. Intensive Care Med 2010; 36: 1235.

21. Mizutani A, Murakami K, Okajima K, et al. Olprinone reduces ischmia/reperfusion-induced acute renal injury in rats through enhancement of cAMP. Shock 2005; 22: 281 .

22. Tosaka S, Makita T, Tosaka R, et al. Cardioprotection induced by olprinone, a phosphodiesterase III inhibitor, involves phosphatidylinositol-3-OH kinase-Akt and a mitochondrial permeability transition pore during early reperfusion. J Anesth 2007; 21: 176.

23. Man K, Lo CM, Ng IO, et al. Liver transplantation in rats using small-for-size grafts: a study of hemodynamic and morphological changes. Arch Surg 2001; 136: 280. 
24. Monbaliu D, Libbrecht L, De Vos R, et al. The extent of vacuolation in non-heart-beating porcine donor liver grafts prior to transplantation predicts their viability. Liver Transpl 2008; 14 : 1256.

25. $\mathrm{Ng} \mathrm{KT,} \mathrm{Man} \mathrm{K,} \mathrm{Ho} \mathrm{JW,} \mathrm{et} \mathrm{al.} \mathrm{Marked} \mathrm{suppression} \mathrm{of} \mathrm{tumor} \mathrm{growth} \mathrm{by} \mathrm{FTY720} \mathrm{in} \mathrm{a} \mathrm{rat}$ liver tumor model: the significance of down-regulation of cell survival Akt pathway. Int J Oncol 2007; 30:375. 


\section{Figure legends}

Figure 1. Scanning electron microscopy (SEM) micrographs $(\times 8000)(\mathrm{A}, \mathrm{C})$ and transmission electron microscopy (TEM) micrographs (B, D) of hepatic sinusoids obtained $1 \mathrm{~h}$ after partial liver transplantation (PLT). (A) In the control group, fenestrae were fused and enlarged, and sinusoidal endothelial cells were disrupted. Hepatocellular microvilli were partly exposed to the sinusoid lumen through the fenestrae. (B) In the control group, endothelial cells and hepatocellular microvilli were disrupted. Vacuolar structures were observed in the hepatocytes. Arrows indicate the vacuolar structures. (C) In the OLP group, fenestrae and sinusoidal cells were well preserved. (D) In the OLP group, endothelial cells were well preserved, whereas hepatocellular microvilli were slightly damaged. No vacuolar structures were observed.

Figure 2. Liver microstructure 1 week after 30\% partial liver transplantation (PLT) (A), after PLT treated with olprinone (B), and after total liver transplantation (C).

Figure 3. Serum levels of aspartate aminotransferase (AST), alanine aminotransferase (ALT), total bilirubin (T-Bil), and hyaluronic acid (HA) determined 1 week after partial liver transplantation.

Figure 4. Kaplan-Meier curves of the control $(n=20)$ and olprinone (OLP; $n=14)$ groups. 

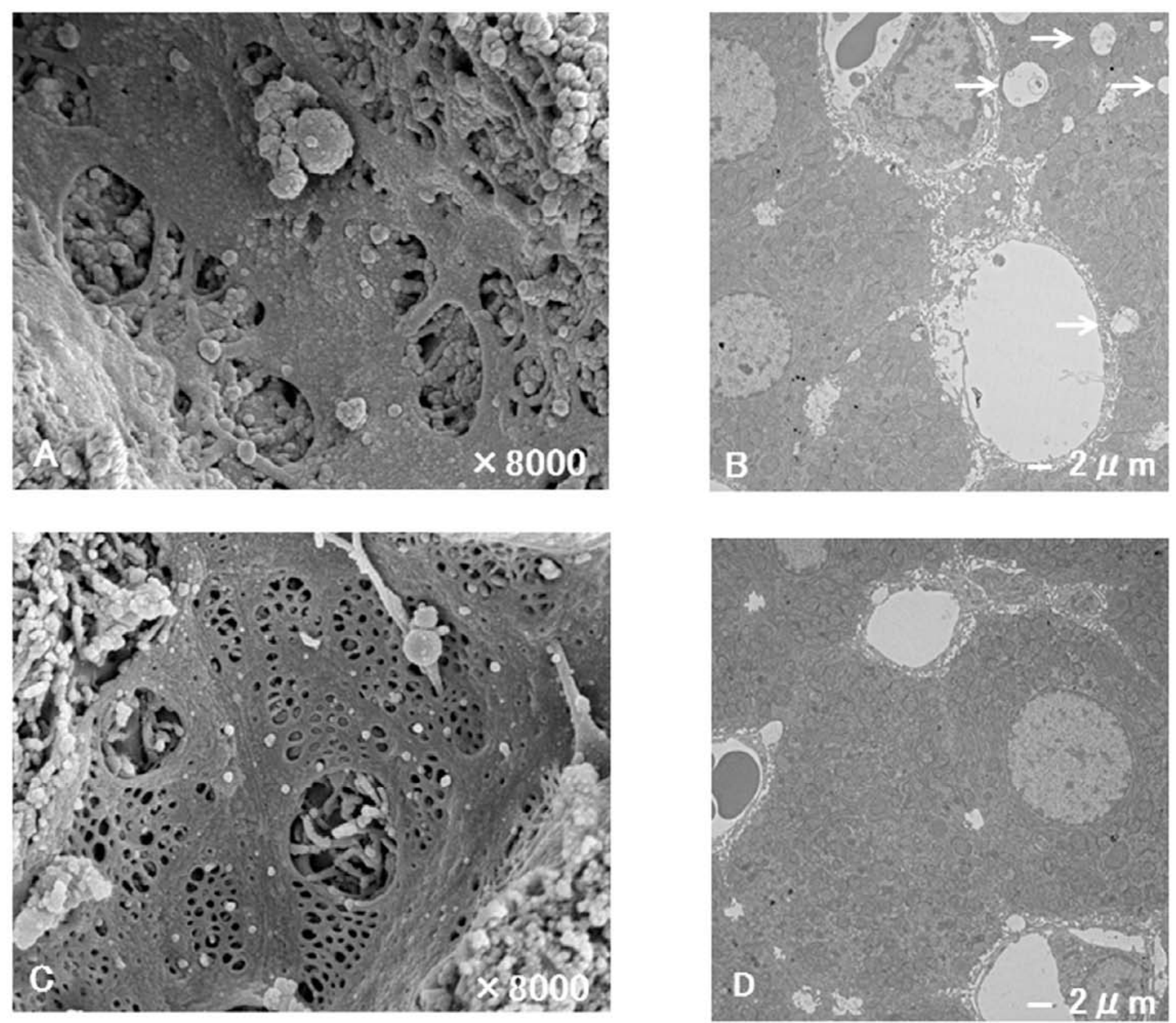

Figure 1 

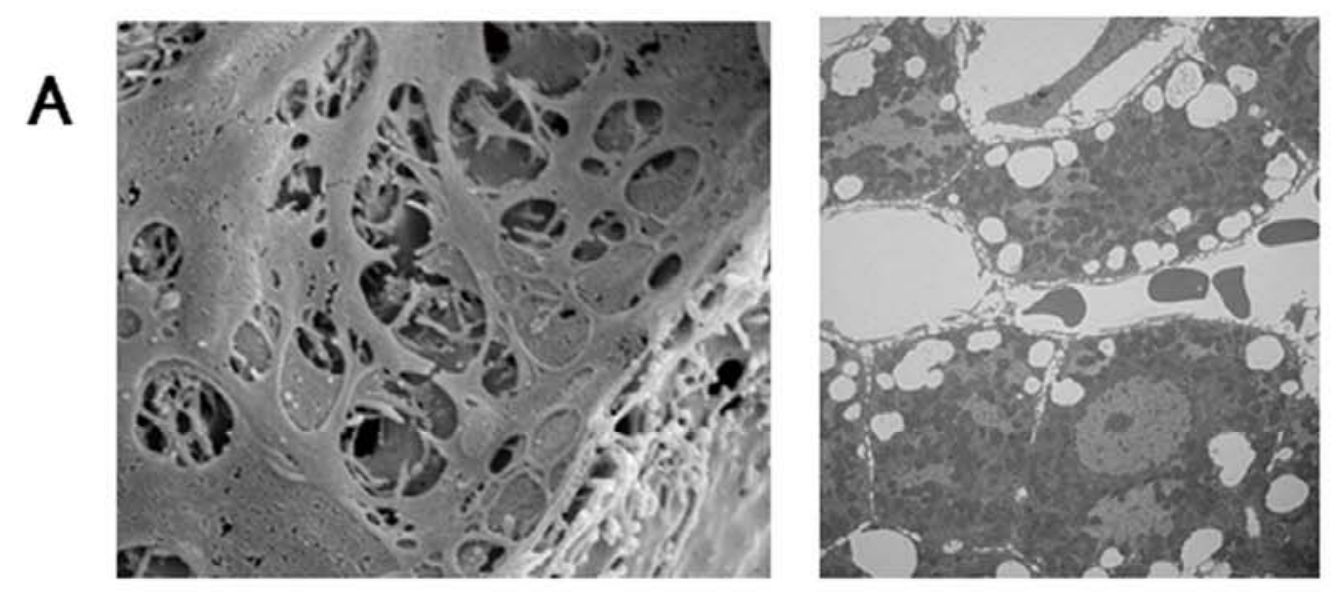

B
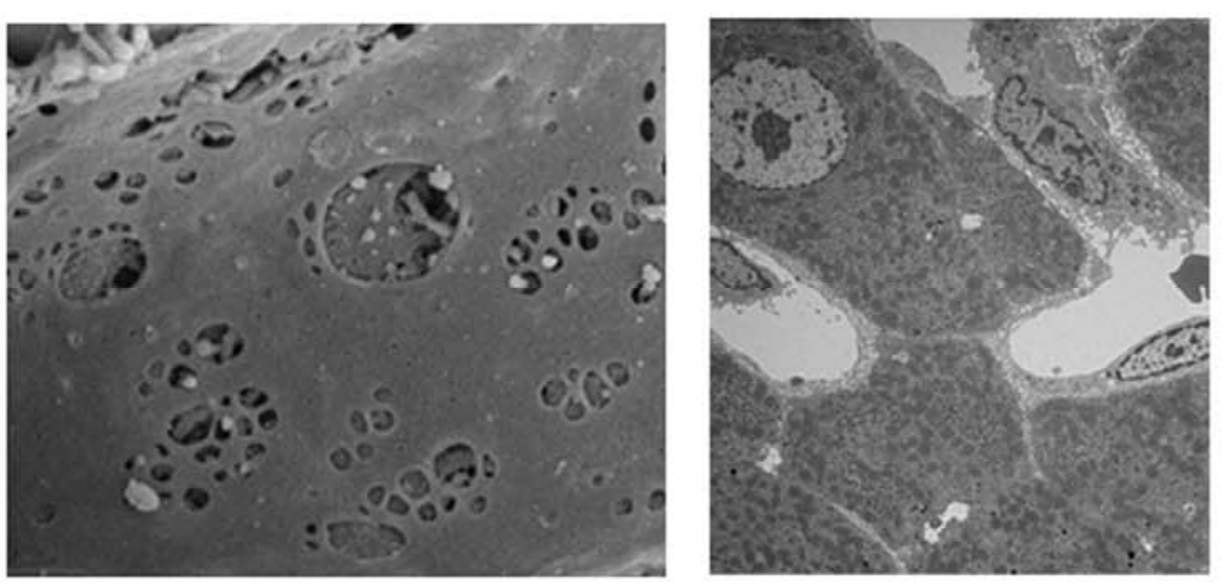

c
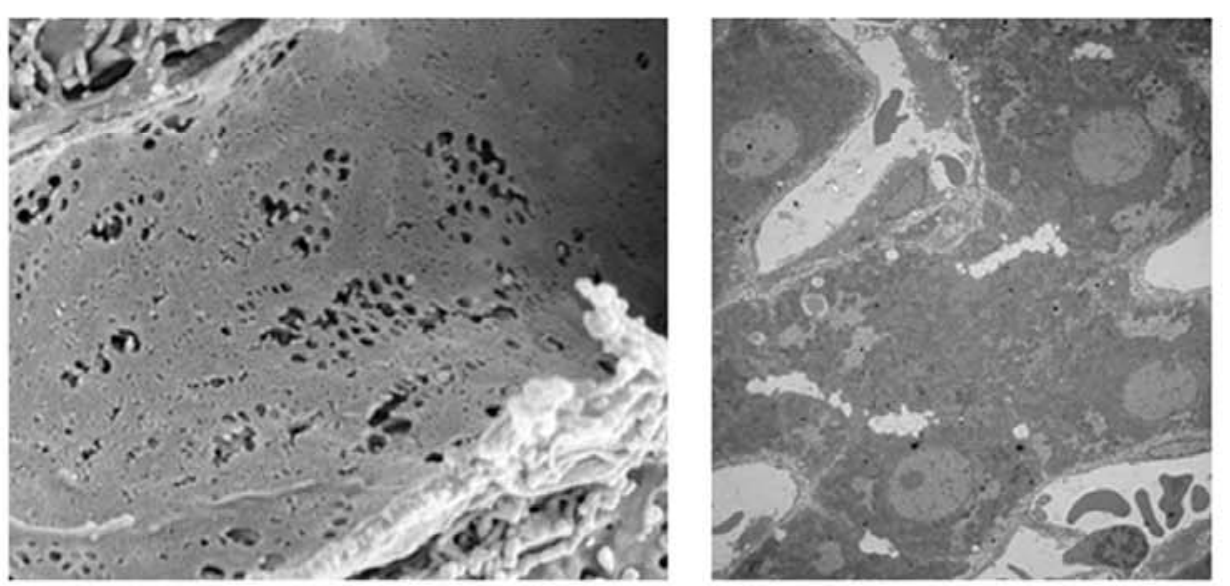

Figure 2 

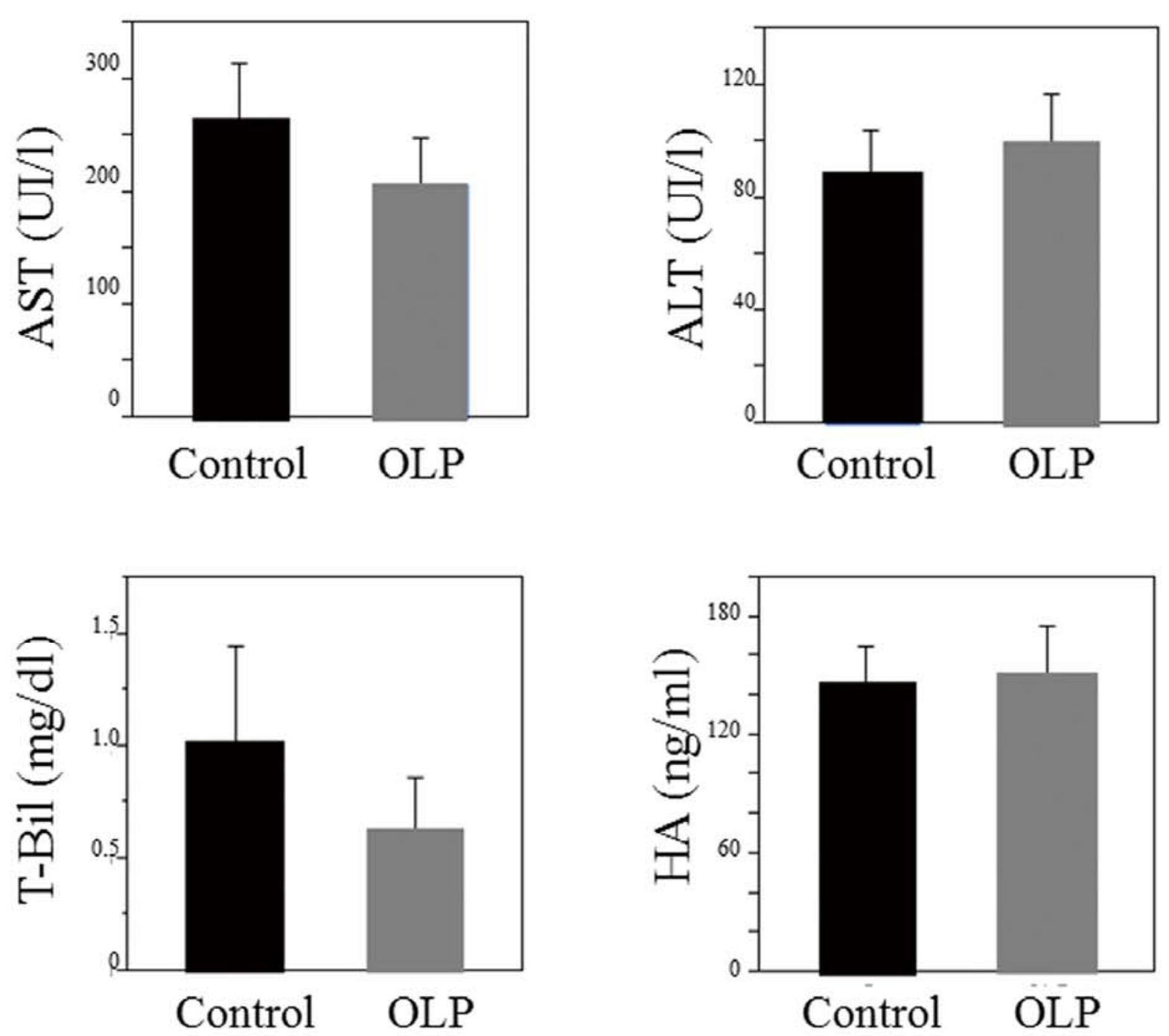

Figure 3 


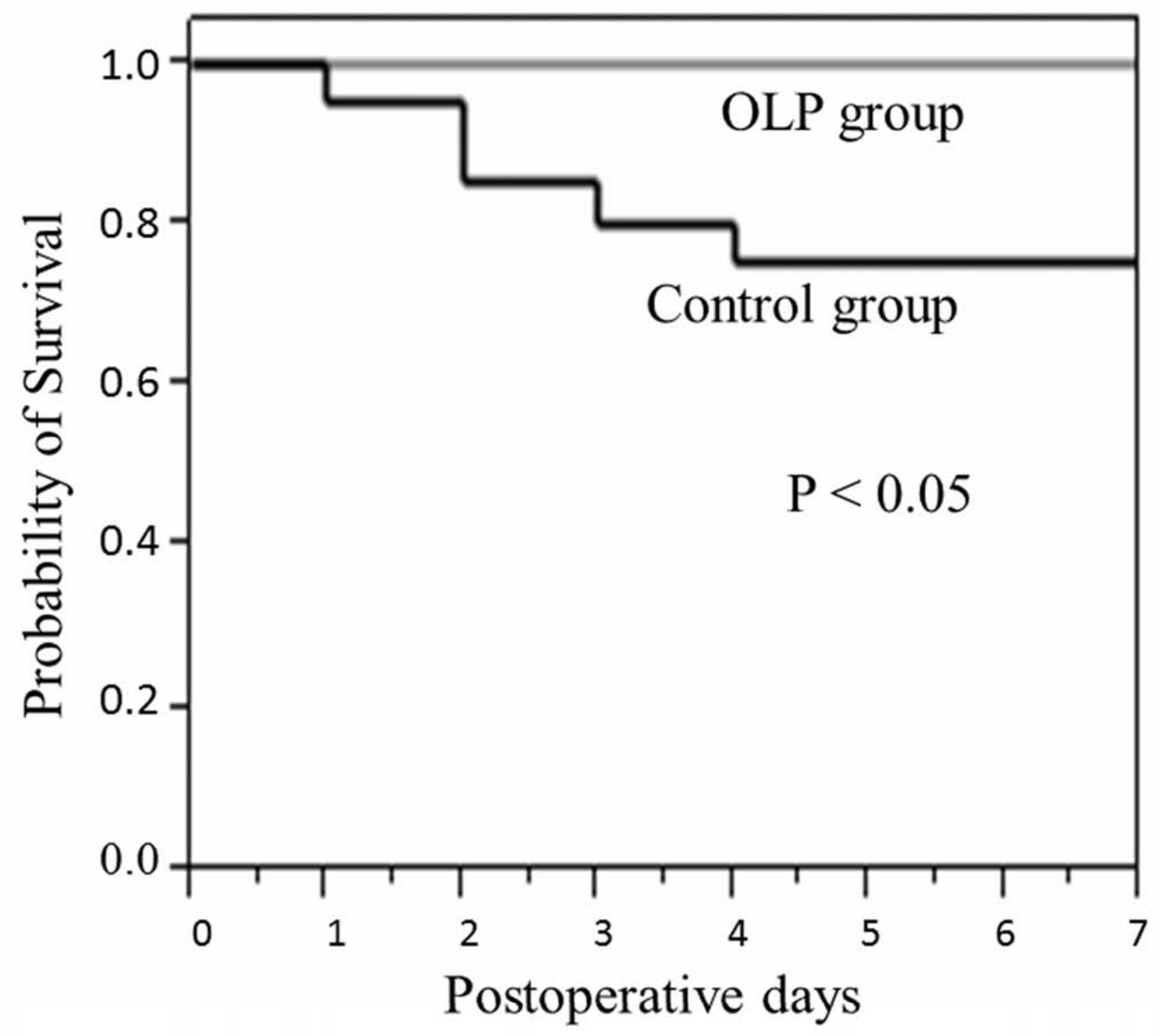

Figure 4 